\title{
Syntrophic acetate oxidation replaces acetoclastic methanogenesis during thermophilic digestion of biowaste
}

\author{
Stefan Dyksma* ${ }^{*}$, Lukas Jansen and Claudia Gallert
}

\begin{abstract}
Background: Anaerobic digestion (AD) is a globally important technology for effective waste and wastewater management. In $A D$, microorganisms interact in a complex food web for the production of biogas. Here, acetoclastic methanogens and syntrophic acetate-oxidizing bacteria (SAOB) compete for acetate, a major intermediate in the mineralization of organic matter. Although evidence is emerging that syntrophic acetate oxidation is an important pathway for methane production, knowledge about the SAOB is still very limited.

Results: A metabolic reconstruction of metagenome-assembled genomes (MAGs) from a thermophilic solid state biowaste digester covered the basic functions of the biogas microbial community. Firmicutes was the most abundant phylum in the metagenome (53\%) harboring species that take place in various functions ranging from the hydrolysis of polymers to syntrophic acetate oxidation. The Wood-Ljungdahl pathway for syntrophic acetate oxidation and corresponding genes for energy conservation were identified in a Dethiobacteraceae MAG that is phylogenetically related to known SAOB. $16 \mathrm{~S}$ rRNA gene amplicon sequencing and enrichment cultivation consistently identified the uncultured Dethiobacteraceae together with Syntrophaceticus, Tepidanaerobacter, and unclassified Clostridia as members of a potential acetate-oxidizing core community in nine full-scare digesters, whereas acetoclastic methanogens were barely detected.
\end{abstract}

Conclusions: Results presented here provide new insights into a remarkable anaerobic digestion ecosystem where acetate catabolism is mainly realized by Bacteria. Metagenomics and enrichment cultivation revealed a core community of diverse and novel uncultured acetate-oxidizing bacteria and point to a particular niche for them in dry fermentation of biowaste. Their genomic repertoire suggests metabolic plasticity besides the potential for syntrophic acetate oxidation.

Keywords: Anaerobic digestion, Metagenome, 16S rRNA gene amplicons, Enrichment cultures, Syntrophic acetateoxidizing bacteria

\section{Background}

Acetate is a central intermediate in the mineralization of organic matter. It is a quantitatively important product that is released by fermentative microorganisms, and its removal is vital for carbon cycling. In methanogenic

\footnotetext{
*Correspondence: stefan.dyksma@hs-emden-leer.de

Faculty of Technology, Microbiology - Biotechnology, University of Applied Sciences Emden/Leer, Emden, Germany
}

environments, the fate of acetate is either to be consumed by acetoclastic methanogens that directly use it for methanogenesis (reaction 1) or it is oxidized by syntrophic acetate-oxidizing bacteria (SAOB). Syntrophic acetate oxidation is dependent on interspecies hydrogen and/or formate transfer in which the syntrophic partner consumes the fermentation products, e.g., a hydrogenotrophic methanogen (reaction 2 and 3). The overall reaction for syntrophic acetate oxidation has the same

C C The Author(s). 2020 Open Access This article is licensed under a Creative Commons Attribution 4.0 International License, which permits use, sharing, adaptation, distribution and reproduction in any medium or format, as long as you give appropriate credit to the original author(s) and the source, provide a link to the Creative Commons licence, and indicate if changes were made. The images or other third party material in this article are included in the article's Creative Commons. licence, unless indicated otherwise in a credit line to the material. If material is not included in the article's Creative Commons licence and your intended use is not permitted by statutory regulation or exceeds the permitted use, you will need to obtain permission directly from the copyright holder. To view a copy of this licence, visit http://creativecommons.org/licenses/by/4.0/ The Creative Commons Public Domain Dedication waiver (http://creativecommons.org/publicdomain/zero/1.0/) applies to the data made available in this article, unless otherwise stated in a credit line to the data. 
stoichiometry as acetoclastic methanogenesis; however, the small amount of energy that is produced by this process $\left(\Delta G^{0^{\prime}}=-31.0 \mathrm{~kJ} / \mathrm{mol}\right)$ [1] needs to be shared by two microorganisms that have to struggle close to the thermodynamic equilibrium.

(1) $\mathrm{CH}_{3} \mathrm{COO}^{-}+\mathrm{H}_{2} \mathrm{O} \rightarrow \mathrm{CH}_{4}+\mathrm{HCO}_{3}^{-}\left(\Delta \mathrm{G}^{0^{\prime}}=-\right.$ $31.0 \mathrm{~kJ} / \mathrm{mol})$

(2) $\mathrm{CH}_{3} \mathrm{COO}^{-}+4 \mathrm{H}_{2} \mathrm{O} \rightarrow 2 \mathrm{HCO}_{3}^{-}+4 \mathrm{H}_{2}+\mathrm{H}^{+}\left(\Delta \mathrm{G}^{0^{\prime}}\right.$ $=+104.6 \mathrm{~kJ} / \mathrm{mol})$

(3) $4 \mathrm{H}_{2}+\mathrm{HCO}_{3}^{-}+\mathrm{H}^{+} \rightarrow \mathrm{CH}_{4}+3 \mathrm{H}_{2} \mathrm{O}\left(\Delta \mathrm{G}^{0^{\prime}}=\right.$ $-135.6 \mathrm{~kJ} / \mathrm{mol}$ )

Anaerobic digestion (AD) is a beneficial technology to treat wastewater sludge and biowaste for the production of renewable energy in the form of methane. Here, acetate is an important precursor for methanogenesis [2]. The constraint that SAOB need to share the energy with a partner methanogen suggests a disadvantage over acetoclastic methanogens such as Methanosarcina and Methanosaeta [3]. Hydrogenotrophic and acetoclastic methanogens generally coexist in AD communities [46] while the Methanosarcina were regularly identified as most abundant and omnipresent [7]. Unlike Methanosaeta that is strictly dependent on acetate, the methane metabolism of Methanosarcina is much more versatile including substrates such as methanol and methylamines as well as hydrogenotrophic growth [8]. Several factors determine the ecological niche of acetoclastic methanogens and their competitors, the SAOB. At elevated temperature, syntrophic acetate oxidation becomes thermodynamically more favorable [9]. The competitive success of SAOB in AD is further affected by the dilution rate and fatty acid concentrations [10-13]. Moreover, high ammonia levels that can be released during the degradation of proteinaceous material were reported to affect or inhibit methanogenesis [14-17]. Unionized free ammonia $\left(\mathrm{NH}_{3}\right)$ is toxic to microorganisms [18]; however, acetoclastic methanogens are generally more sensitive to ammonia than the hydrogenotrophic ones [19-21]. Under these high ammonia conditions, syntrophic acetate oxidation can become the dominant process for acetate consumption although acetoclastic methanogenesis proceed concurrently [22-27].

Acetate-consuming methanogens are fairly well studied, but comparatively, little is known about the physiology and ecology of SAOB. Only few isolated species are described so far: the mesophilic Clostridium ultunense [28], Syntrophaceticus schinkii [29], Ca. Syntrophonatronum acetioxidans [30], the thermotolerant Tepidanaerobacter acetatoxydans [31], and the thermophilic Pseudothermotoga lettingae [32] and Thermacetogenium phaeum [33]. All described species can also grow axenically as heterotrophs-producing acetate from a variety of substrates or even grow autotrophically through homoacetogenesis as reported for $T$. phaeum [33]. Although the majority of SAOB were isolated from biogas reactors, syntrophic acetate oxidation is important for carbon cycling in natural environments beyond AD such as sediments [34-36], oil-reservoirs [37], and soils $[38,39]$.

In this study, we targeted microorganisms involved in acetate turnover from nine thermophilic biogas reactors that treat biowaste in dry-fermentation. 16S rRNA gene amplicon sequencing consistently identified Syntrophaceticus while acetoclasic methanogens were barely detected. In enrichment cultures, known genera of SAOB (Tepidanaerobacter and Syntrophaceticus) were detected but also Clostridia distantly related to Caldicoprobacter were highly enriched. Potential mechanisms of carbon cycling in these biogas reactors were further characterized using metagenome sequencing. Therefore, we built an automated metagenome analysis pipeline embedded in a Snakemake workflow. Along with the qualities of Snakemake [40], this pipeline is transferable, easily customizable, and scalable for much more complex datasets. Raw read processing, assembly, binning, annotation all the way to phylogeny of metagenome-assembled genomes (MAGs), and detailed reporting are automated in a customizable workflow. It is available at github.com/ KnuttPipeline. Together, the enrichment cultures and the cultivation-independent approaches gained insights into an unusual methanogenic community of $\mathrm{AD}$ systems that represent a particular niche for syntrophic acetate-oxidizing bacteria.

\section{Results and discussion}

\section{Genomic potential in thermophilic dry fermentation of biowaste}

A total of $\sim 645$ megabases of quality trimmed metagenomic sequencing data was recovered from a thermophilic digester that treats biowaste. Both $16 \mathrm{~S}$ rRNA gene fragments extracted from the metagenome and total quality trimmed reads were used for taxonomic assignment (Fig. 1a, Additional file 2: Supplementary Methods). Classification of reads that could be mapped to a $16 \mathrm{~S}$ rRNA gene reference database revealed Firmicutes as dominant bacterial phylum (53.2\%) followed by Bacteroidetes (11.1\%) and Thermotogae (7.7\%). All other bacterial phyla together accounted for $11.8 \%$ (Fig. 1a). Archaea contributed 3.1\% to the prokaryotic community and was strikingly dominated by the genera Methanoculleus (2.6\%) and Methanothermobacter (0.4\%) (Fig. 1a, Additional file 1: Fig. S2). Assembly and binning allowed the reconstruction of 14. MAGs that showed more than $60 \%$ of marker gene completeness although the sequencing depth was rather low, which is indicated by the average assembly coverage of 4.7 -fold. MAGs could be 
a

All reads (outer ring)

16S rRNA fragments (inner ring)

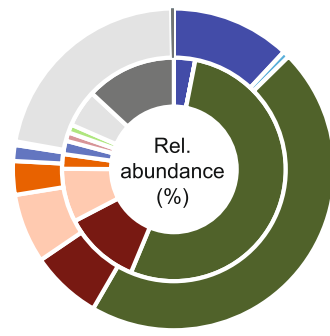

- Euryarchaeota - Halanaerobiota

- Other Archaea $=$ Tenericutes

- Firmicutes $\quad$ Atribacteria

- Bacteroidetes Other

-Thermotogae -Unclassified

- Synergistetes

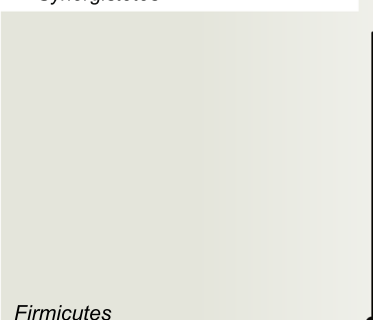

Firmicutes

Halanaerobiota

Thermotogae

Candidatus Atribacteria

Bacteroidetes

-

Synergistetes

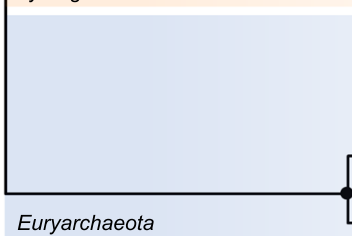

Euryarchaeota b

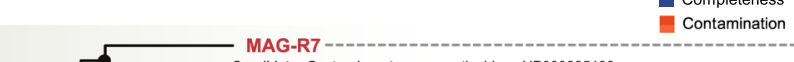

MAG-R7 --- Mandidatus Syntrophonatronum acetioxidans UP00028513
Dethiobacter ralkaliphilius UP000000443 Anaerobranca callifomiensis UP000243547

Peptococcaceae bacterium UP000264096

- Thermanaeromonas toyohensis UP000192569

UP 000197032

Clostridiales bacterium PH28-bin88 UP000034222

MAG-E2 Syntrophomonas zehnderi UP000045545

Syntrophomonas wolfei subsp. wolfei UP00000196

MAG-R1
Thermosyntropha lipolytica UP000242329

Syntrophothermus lipocalidus UP 000000378
Syntrophaceticus schinkii UP000046155

Thermacetogenium phaeum UP000000467

- Desulfitobacterium hafniense UP000054623

Sporolituus thermophilus UP 000243333

Caloranaerobacter azorensis UP000183967
Thermohalobacter berrensis UP000284177

Proteiniborus sp. DW1 UP000185208

Thermotalea metallivorans

MAG-E1 -

- $[$ Thermoanaerobacter kivui UP000029669

Thermoanaerobacter uzonensis UP000184127

Caldanaerobacter subterraneus UP0002948

Caldicoprobacter faecalis UP000198577

MAG-R3
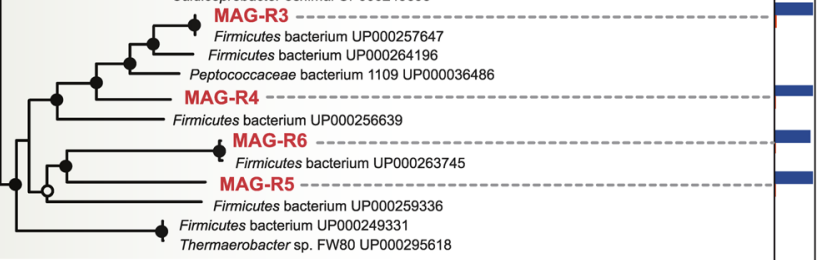

Completeness

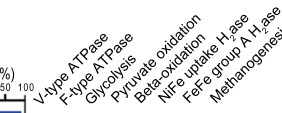

\begin{tabular}{|l|l|l|l|}
\hline$\square \mid$ & $\mid$
\end{tabular}
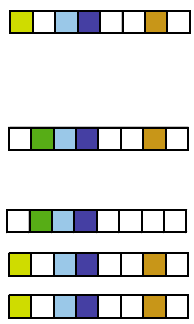

aerobacter sp. FW80 U

- Halanaerobium saccharolyticum UP00024408 Halanaerobium salsuginis UP000199006

Halocella sp. SP3-1

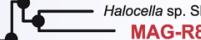

Hothe

Defluvitoga tunisiensis UP000032809 MAG-R13 --- 13 Petrotoga sp. 9PWA UP00023655 Petrotoga sibirica UP000294817

$\sum$ Petrotoga sibirica U

Kosmotoga olearia UP000002382

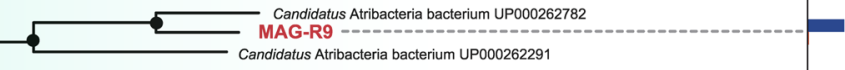

$\square \square \square \square$

Dysgonamonadaceae bacterium UP000234415 Porphyromonad dace 10 -- becterium UP000262298

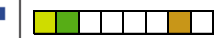
Porphyromonadaceae bacterium UP00026354 Dysgonomonas capnocytophagoides UP000297861 Marinifilum breve UP000248079 Saccharicrinis fermentans UP00001940 Bacteroidales bacterium UP000263498 MAG-R11 --------- Bacteroidetes bacterium HGW-6 UP000233 Marinilabiliales bacterium UP000243331 Marinilabiliales bacterium UP000243028 Marinilabiliales bacterium UP000243286

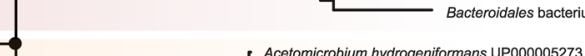

Acetomicrobium hydrogeniformans UP0000052

Acetomicrobium mobile UP000006061

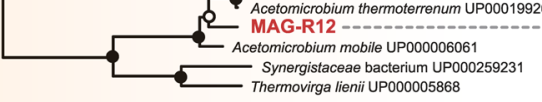

Methanoculleus marisnigri UP000002146 Methanoculleus sp. MHISA UP00002717 Methanoculleus so. Mists UP000035301

- - Methanoculleus bourgensis UP000009007 - MAG-R14 Methanoculleus sp. SDB UP00005174 Methanococcoides vulcani UP000243338 Methanosarcina thermophila UP00026555

Fig. 1 (See legend on next page.) 
(See figure on previous page.)

Fig. 1 Taxonomic assignment of quality trimmed metagenome reads summarized on phylum level (a) based on total reads (outer ring) and 16S rRNA gene fragments (inner ring). Phylogeny of metagenome assembled genomes based on concatenated marker protein sequences and selected metabolic functions encoded in their genomes (b). Further information about contamination and completeness of the MAGs is provided in Additional file 1: Table S1. RAxML bootstrap support > 70\% is indicated by open circles, and bootstrap support $>90 \%$ is indicated by closed circles. Multifurcations were introduced for branches with bootstrap support $<50 \%$

recovered from almost all major phyla that were identified from total metagenome reads (Fig. 1a), and $57 \%$ of the metagenome reads could be mapped back to the MAGs. The phyla Atribacteria, Bacteroidetes, Halanaerobiota, Firmicutes, Synergistetes, and Thermotogae were represented in the metagenome by at least one medium-quality MAG (> $50 \%$ complete). The majority of MAGs (7 out of 14) affiliated with the dominant phylum Firmicutes. Most of the MAGs contained less than $4 \%$ contamination, though the Methanoculleus MAG-R14 showed a duplication of almost all single copy marker genes (Additional file 1: Table S1). Moreover, the Defluviitoga MAG-R13 (Thermotogae) contained 14\% contamination from closely related species. Concatenated ribosomal proteins and the taxonomic assignment of the annotated coding sequences (CDS) were used for a more detailed phylogenetic identification of the MAGs (Fig. 1b). A comparison of the common modules and those that were mostly absent suggests that fermentation rather than respiration account for the majority of carbon mineralization (Fig. 1b), which agrees with the very low concentration of common electron acceptors typically found in $\mathrm{AD}$ systems. Moreover, the most widespread hydrogenases found in the MAGs and most abundant in unbinned metagenome sequences were electron confurcating group A3
[FeFe] hydrogenases (Additional file 1: Fig. S1) that couple the fermentative evolution of hydrogen from NADH with the oxidation of reduced ferredoxin [41].

$\mathrm{AD}$ of organic matter starts with the depolymerization of macromolecular material. Biowaste can be rich in polymers derived from plant material like cellulose. The large fraction of Defluviitoga (MAG-R13) in this system indicates the relevance of these bacteria for the hydrolysis of polysaccharides. Defluviitoga utilize a remarkable variety of complex carbohydrates such as xylan, pullulan, lichenan, galactan, chitin and cellulose, among others $[42,43]$ producing acetate, ethanol, hydrogen, and carbon dioxide. Defluviitoga tunisiensis was also identified as widespread and abundant suggesting a central role in thermophilic biogas reactors [44]. Among the highest number of intracellular and extracellular carbohydrateactive enzymes (CAZymes) were identified in the Defluviitoga MAG-R13, which further support their importance for the initial breakdown of macromolecular compounds (Fig. 2). In addition, genes involved in oligosaccharide and sugar degradation as well as the relevant transporters were prevalent among the bacterial MAGs. This is in coherence with a high functional redundancy that has been reported for the first steps of $\mathrm{AD}$ and $\mathrm{a}$

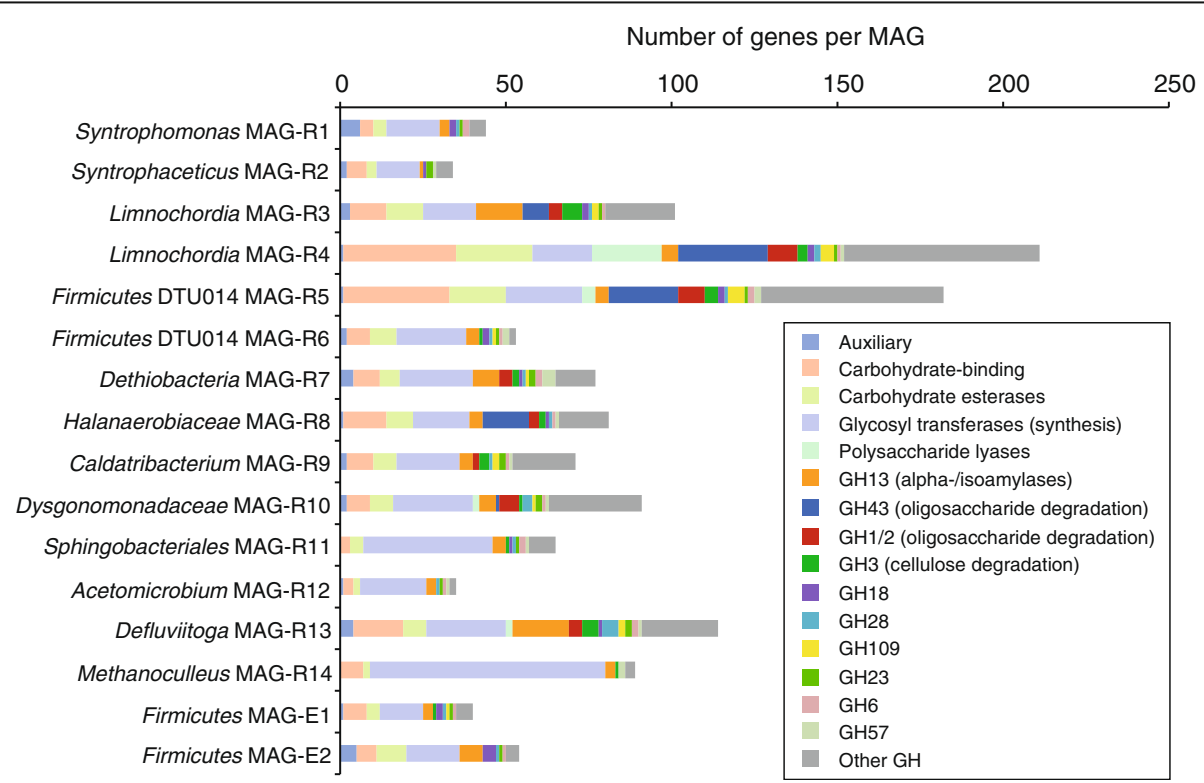

Fig. 2 Number and groups of carbohydrate active enzymes identified in the MAGs. Major functions associated with selected groups are indicated. Glycosyl hydrolase families $(\mathrm{GH})$ primarily include carbohydrate degrading enzymes 
gradually more specialized community in the later steps of AD [44-46]. Several complete modules for amino acid metabolism and degradation were detected in the Sphingobacteriales MAG-R11 suggesting uncultured Bacteroidetes as degrader of proteinaceous material besides their capability to utilize carbohydrates (Fig. 2). Genes for dissimilatory sulfur metabolism (sat and apr) were only identified in Halanaerobiaceae MAG-R8, but their sulfurmetabolizing capacity remains unclear as closely relates species such as Halocella cellulolytica and Halothermothrix orenii were described as obligate-fermenting bacteria $[47,48]$. The final step of AD in this system is facilitated by hydrogenotrophic methanogens of the genera Methanoculleus (MAG-R14) and Methanothermobacter (Fig. 1a, Additional file 1: Fig. S2) that potentially act as syntrophic partner for the bacteria described below.

\section{Metagenomic perspective on syntrophy and microbial interactions}

Several MAGs were assigned to syntrophic or putatively syntrophic bacteria (Fig. 3). Here, we particularly focused on $\mathrm{SAOB}$ as acetoclastic methanogens were not detected in the MAGs and unassembled metagenome reads (Fig. 1 ), which suggests that acetate is mainly turned over by bacteria.

Evidence from biochemistry and transcriptomics revealed that some SAOB use the reversed WoodLjungdahl (WL) pathway for acetate oxidation [49-52]. The WL pathway can operate in both the reductive and oxidative direction, and diverse acetogenic bacteria use this pathway to produce acetyl-CoA from $\mathrm{CO}_{2}$ with various electron donors or use the pathway as electron sink during carbohydrate or organic acid fermentation [53]. WL pathway genes of SAOB were usually scattered in the genome not organized in an operon structure [54], and based on gene homology, it is further not possible to predict if the pathway could be reversed for acetate oxidation [52]. Therefore, it is not possible to identify SAOB from coding information in their genome alone. Phylogenetic analysis of ribosomal proteins revealed Syntrophaceticus MAG-R2 most closely related to the well characterized SAOB Syntrophaceticus schinkii and

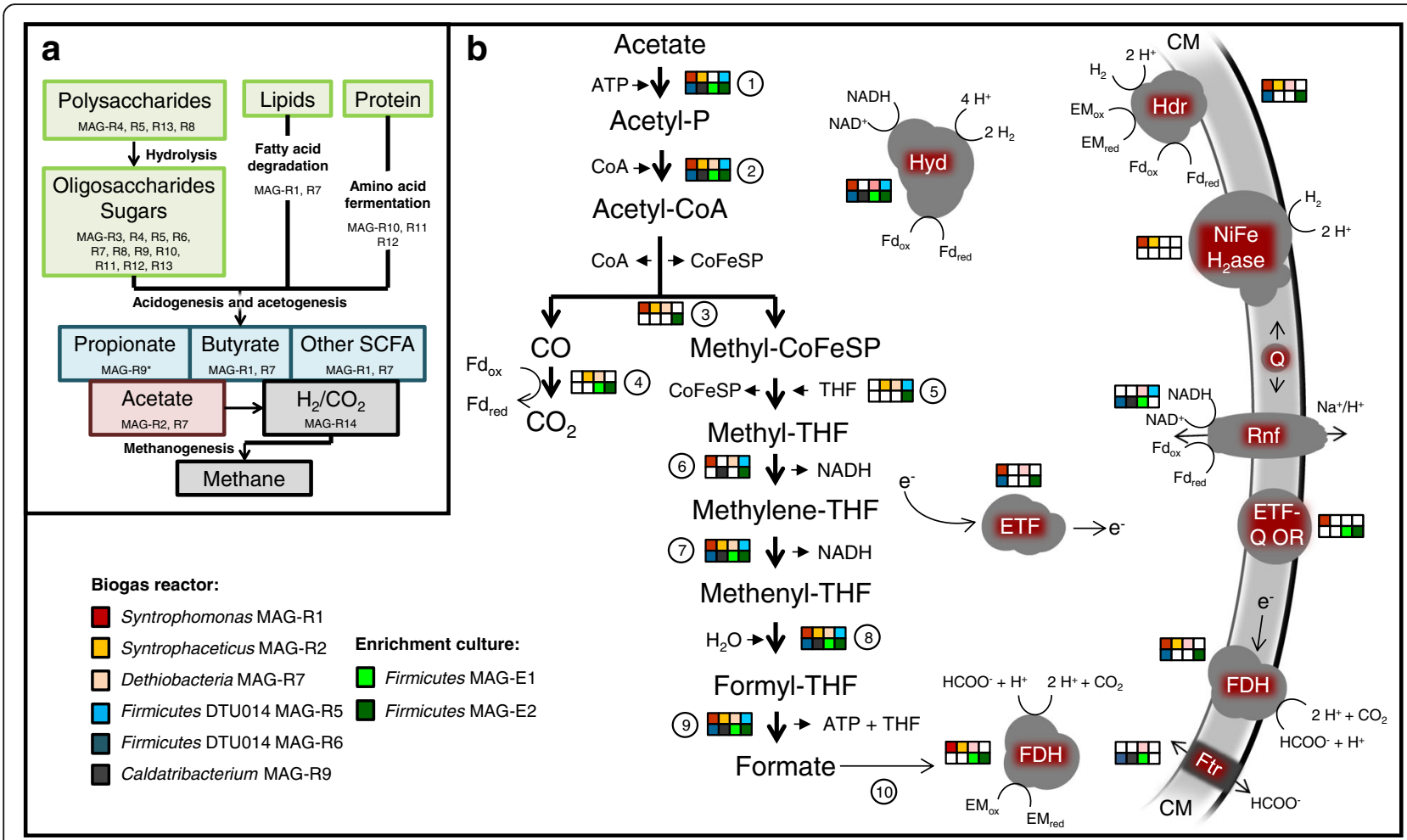

Fig. 3 Putative functions of the MAGs in the anaerobic digestion food web (a). The asterisk (MAG-R9) indicates a potential function that merely proposed in literature (see text for details). Wood-Ljungdahl pathway genes in MAGs of syntrophic and putatively syntrophic bacteria as well as the corresponding energy-conserving mechanisms (b). Hyd, [FeFe] hydrogenase group A3; Hdr, heterodisulfide reductase; NiFe H2ase, energyconserving group 1a [NiFe] hydrogenase; $\mathrm{Rnf} \mathrm{Na}^{+} / \mathrm{H}^{+}$translocating ferredoxin: $\mathrm{NAD}^{+}$oxidoreductase; Q, quinone; ETF, electron transfer flavoprotein; ETF-Q OR, electron transfer flavoprotein/quinone oxidoreductase; FDH, formate dehydrogenase; Ftr, formate transporter; EM, electron mediator; CM, cytoplasmic membrane; THF, tetrahydrofolate. Genes involved in the Wood-Ljungdahl pathway are acetate kinase (1), phosphotransacetylase (2), acetyl-CoA synthase complex including corrinoid protein (CoFeSP) (3), carbon monoxide dehydrogenase (4), methyltransferase (5), methylene-THF reductase (6), methylene-THF dehydrogenase (7), methenyl-THF cyclohydrolase (8), formyl-THF synthethase (9), and formate dehydrogenase (10) 
Thermacetogenium phaeum (Fig. 1b). Although the MAG showed only 64\% marker gene completeness, it contained the WL pathway except a methylenetetrahydrofolate (methylene-THF) reductase gene that is missing (Fig. 3b). Moreover, MAG-R2 shared several genes encoding energy conservation mechanisms with $S$. schinkii and $T$. phaeum including the respiratory group 1a [NiFe] hydrogenase that is absent in the other known SAOB [54]. The genomic repertoire for syntrophic acetate oxidation was further identified in Dethiobacteria MAG-R7. The $89 \%$ complete MAG only lacked the gene for acetate activation, the acetate kinase (Fig. 3b). In the oxidative WL pathway, one ATP has to be invested for acetate activation, and substrate level phosphorylation of methyl-THF to formate would yield one ATP. Thus, there is no net ATP gain and it is still unknown how SAOB conserve energy. To circumvent energyconsuming acetate activation by an acetate kinase to acetyl phosphate, an alternative route via acetaldehyde was recently proposed for T. phaeum [55, 56]. Dethiobacteria MAG-R7 contained several genes encoding an aldehyde ferredoxin oxidoreductase that could enable this alternative way of acetate activation, or the acetate kinase gene is missed in the assembly. A nearly complete 16S rRNA gene was encoded in MAG-R7 that further confirmed the phylogenetic placement based on ribosomal proteins. Interestingly, MAG-R7 grouped with $\mathrm{Ca}$. Syntrophonatronum acetioxidans, a SAOB important in haloalkaline environments [30, 57]. Ca. Contubernalis alkalaceticum, another haloalkaliphilic bacterium that was described as SAOB [58], and other syntrophic Dethiobacteraceae [57] were closely related to MAG-R7. Together, the phylogeny and the genomic repertoire for syntrophic acetate oxidation suggest the Dethiobacteria MAG-R7 as a potential SAOB. Besides carbohydrate fermentation, a complete beta-oxidation pathway was found in MAG-R7 suggesting a high metabolic flexibility potentially including fatty acid degradation (Fig. 1b, Fig. 2).

Mosbæk et al. [59] suggested members of the DTU014 clade (Firmicutes) as SAOB. Protein-based stable isotope probing combined with metagenomics identified heavily labeled proteins affiliating with the DTU014 in incubations with ${ }^{13} \mathrm{C}$-labeled acetate although a complete $\mathrm{WL}$ pathway was not identified in the respective genome bins [59]. Both DTU014 MAGs obtained in this study (R5 and R6) shared > 99\% average nucleotide identity with the MAGs reported by Mosbæk et al. [59] and also lack key genes such as the carbon monoxide dehydrogenase/acetyl-CoA synthase complex including the corrinoid iron sulfur protein (Fig. 3b). The oxidative WL pathway is so far the only known route used by SAOB to drive acetate oxidation. However, not all isolated and characterized SAOB encode the complete gene set for this pathway as well. The genomes of four isolated
SAOB are completely sequenced, but Clostridium ultunense and Pseudothermotoga lettingae lack several genes of the WL pathway indicating that other pathways for syntrophic acetate oxidation could exist. Consequently, acetate-oxidizing DTU014 might use such an alternative route. Low energy yield and slow growth rates of syntrophic SCFA-oxidizing bacteria could be a possible explanation that those organisms were often found in low abundances in AD. The high coverage of DTU014 MAG-R5 and MAG-R6 together with their large fraction of $16 \mathrm{~S}$ rRNA gene fragments (Additional file 1: Table S1, Fig. S2) indicate a high abundance of these species, which contradicts the typical proportions of SAOB in $\mathrm{AD}$ communities and rather points to a function different than syntrophic acetate consumption in this biogas reactor.

Other potential syntrophs identified in the metagenome were Caldatribacterium (MAG-R9) and Syntrophomonas (MAG-R1) species. The putative functions of the poorly characterized candidate phylum Atribacteria are as yet little understood. Atribacteria associated with AD were proposed as syntrophic propionate-oxidizing bacteria based on metagenomics and transcriptomics [60, 61]; however, genes encoding the methylmalonyl-CoA pathway for propionate oxidation were largely absent in Caldatribacterium MAG-R9. Saccharolytic fermentation and syntrophic acetate oxidation via a hypothetical pathway using the glycine cleavage system was also proposed $[61,62]$. There is as yet no experimental evidence for syntrophic acetate oxidation among the Atribacteria, and physiological inferences are almost exclusively based on metagenome data. MAG-R1 affiliated with cultured Syntrophomonas species (Fig. 1b). Like the isolated relatives, Syntrophomonas MAG-R1 appears to be specialized for the degradation of fatty acids using the betaoxidation pathway. MAG-R1 and MAG-R9 did not encode a WL pathway and thus likely did not belong to the acetate-degrading community (Fig. 3b).

\section{Potential for syntrophic acetate oxidation in enrichment cultures}

Mineral medium containing no electron acceptors other than bicarbonate $/ \mathrm{CO}_{2}$ was inoculated from a thermophilic biogas reactor (Additional file 1: Table S2). Acetate was repeatedly fed to a concentration of $10 \mathrm{mM}$. The cultures were incubated at $55^{\circ} \mathrm{C}$ and $1-10 \%$ was regularly transferred into fresh medium. After 117 days of incubation and three successive transfers, the active cultures were selected for amplicon sequencing to identify the acetate-consuming microbial community (Fig. 4). The enrichments ENR-ALA, ENR-AEA, and ENR-Ac were inoculated from the same reactor but treated slightly different (see "Methods" section for details). Bacteria known as SAOB such as Syntrophaceticus and 
Tepidanaerobacter were enriched but also acetoclastic methanogens of the Methanosarcina (Fig. 4). In ENRAc, Firmicutes classified as Caldicoprobacter and Methanosarcina were enriched whereas known SAOB could not be detected. Active acetate-degrading enrichment cultures with no known SAOB were selected, and cultivation was pursued in the same way (ENR-Ac). The microbial communities were screened again after 211, 244, and 491 days of incubation. Caldicoprobacter-related bacteria were enriched from $2 \%$ relative abundance in the inoculum up to $63 \%$ and were consistently identified as the dominant microbial group in these cultures although their relative abundance was fluctuating (Fig. 4). Even though it is unclear if the detected Methanosarcina performed acetoclastic or hydrogenotrophic methanogenesis, the presence of strictly hydrogenotrophic Methanothermobacter strongly suggest syntrophic acetate oxidation. In addition, uncultured Anaerolineaceae (Chloroflexi), Symbiobacterium, and Acetomicrobium were also enriched in the culture ENR-Ac (Fig. 4; Additional file 1: Fig. S3). Uncultured Anaerolineaceae were previously linked to homoacetogenesis in $\mathrm{AD}$ using a combined metagenomics and transcriptomics approach [63]. The high acetate concentrations fed to the cultures and phases of starvation were stress factors for the microbes. Such phases of imbalance might allow the coexistence of homoacetogenic bacteria, SAOB, acetoclastic, and hydrogenotrophic methanogens. Acetomicrobium was identified in all cultures and was often among the most abundant. The partial 16S rRNA sequence of the dominant OTU ( $\sim 400 \mathrm{bp}$ length) from the enrichment cultures was closely related to A. hydrogeniformans (> 99\% identity), which was described to ferment simple sugars and amino acids [62]. We tested all three related species (A. hydrogeniformans DSM22491, A. thermoterrenum DSM13490, and $A$. mobile DSM13181) with both Methanoculleus thermophilus DSM2373 and Methanothermobacter thermoautotrophicus DSM1053 in a defined co-culture for syntrophic growth on acetate. Moreover, the Acetomicrobium sp. purified from our enrichment cultures was also tested for growth with both methanogens. Under the applied conditions, no acetate consumption or methane formation was observed for any of the defined co-cultures. Interestingly, Acetomicrobium was also enriched in thermophilic propionatedegrading enrichment cultures inoculated from the same biogas reactor [64]; however, their role in these syntrophic communities still remains enigmatic.

Enrichment ENR-Ac was further sampled at day 244 for metagenome sequencing. Two largely complete MAGs with less than $2 \%$ contamination (Additional file 1: Table S1) that affiliated with Firmicutes were recovered from the metagenome. Both MAGs did not contain $16 \mathrm{~S}$ rRNA gene fragments that could be used for phylogenetic identification. Based on ribosomal proteins, MAG-E1 was distantly related to Caldicoprobacter sp., whereas MAG-E2 was related to Calderihabitans maritimus (Fig. 1b). Amplicon sequencing revealed that the clade assigned to Caldicoprobacter was dominated by two major OTUs at day 491. Together with the coverage information (Additional file 1: Table S1), this suggest that the MAGs E1 and E2 represented the dominant species of the Caldicoprobacter clade. Firmicutes MAGE1 that showed $97.6 \%$ marker gene completeness lacked central genes of the WL pathway whereas a complete WL pathway could be identified in MAG-E2 (Fig. 3b). A

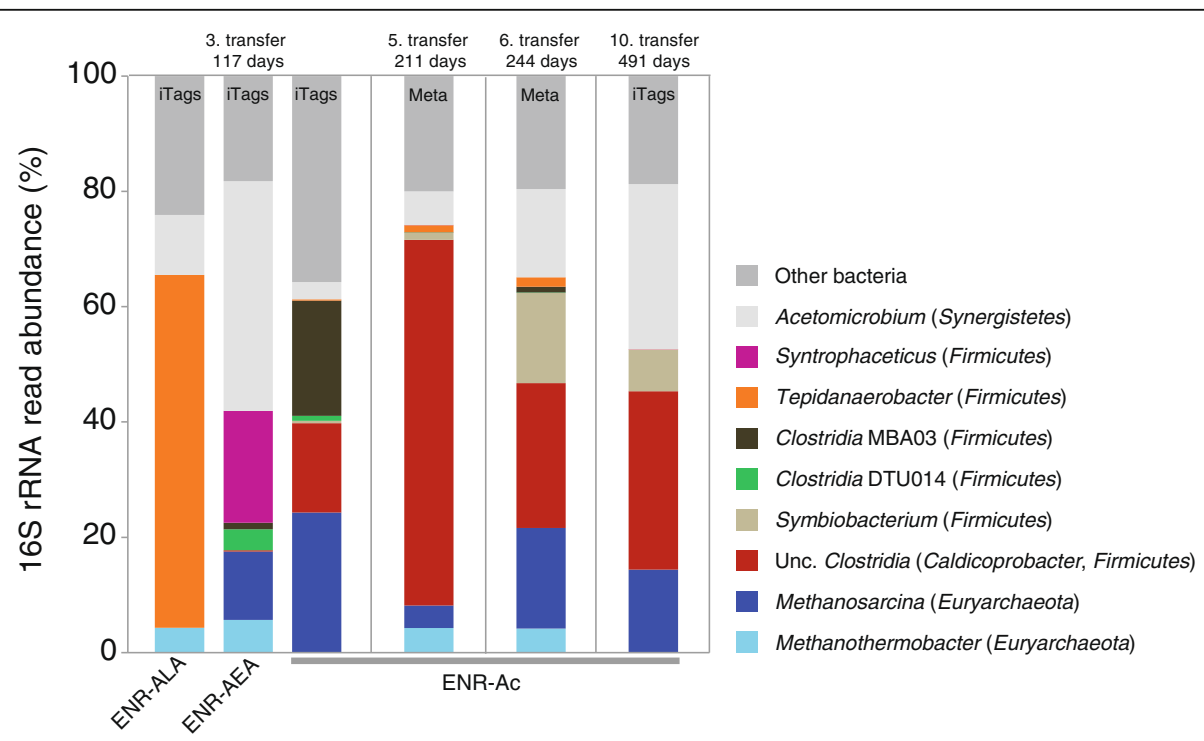

Fig. 4 Relative abundance of major bacterial and archaeal groups in acetate-fed enrichment cultures. The microbial community was either analyzed by 165 rRNA gene amplicon sequencing (iTags) or metagenome sequencing (Meta) 
comparison of their genomic repertoire revealed that the metabolism of MAG-E2 is more versatile (Figs. 1b, 2, $3 \mathrm{~b})$. Central genes of butyrate and propionate metabolism, carbohydrate fermentation, beta oxidation, and amino acid metabolism were detected. Moreover, a respiratory complex I, genes for a dissimilatory sulfite reductase (DsrAB) together with DsrCJKMOP as well as a truncated denitrification pathway including nitrate reductase, nitrite reductase, and nitric-oxide reductase were encoded in the genome (Additional file 1: Fig. S4, Fig. S5). This strongly suggests that MAG-E2 can utilize various electron acceptors. The MAG-E2 contained genes encoding a NAD-dependent FDH and a FDH complex (Fig. 3b) that is likely membrane associated and periplasmatically oriented as indicated by a TAT (twinarginine translocation) signal peptide as well as transmembrane helices. The structure of this complex is comparable to the membrane-bound FDH of Thermacetogenium phaeum, which is only expressed during syntrophic growth on acetate [55]. Reverse electron transport could be driven in a similar manner to that of Syntrophomonas wolfei when growing syntrophically on butyrate [65-67]. Electrons may be shuttled by an electron transfer flavoprotein (ETF) to an ETF-quinone oxidoreductase that reduces the quinone pool. The periplasmatically oriented FDH complex could then reoxidize the reduced quinone pool. MAG-E2 further encodes an electron confurcating FeFe-hydrogenase group A3 (Ech) and a heterodisulfide reductase (Hdr) complex that is possibly involved in reverse electron transport (Additional file 1: Fig. S4). Stable isotope probing further suggested Caldicoprobacter-related Firmicutes as acetate-oxidizing bacteria in thermophilic methanogenic communities fed with ${ }^{13} \mathrm{C}$-labeled acetate [68]. The major fraction of the heavily labeled bacterial DNA was assigned to the Caldicoprobacter-related organisms [68]. $\mathrm{SAOB}$ are fastidious and slow growing bacteria that are difficult to culture. So far, no SAOB were isolated together with hydrogenotrophic methanogens from our enrichment cultures. Thus, additional research is indispensable to confirm syntrophic acetate metabolism among these uncultured bacteria and to unravel their mechanism for syntrophy.

\section{Amplicon sequencing revealed stable bacterial and archaeal communities in thermophilic dry-fermentation of biowaste}

To examine if the identified putatively $\mathrm{SAOB}$ were a regular component of the microbial community in thermophilic solid-state digestion of biowaste, we selected nine full-scale anaerobic reactors located in Germany and the Netherlands for 16S rRNA gene amplicon sequencing (iTags) of the $\mathrm{V} 3-\mathrm{V} 4$ region (> $400 \mathrm{bp}$ ). The reactor that was used for metagenomic analysis was also included for the amplicon sequencing approach (PFL9). The combination of amplicon sequencing and metagenomics enabled us to link the metabolic insights to a stable core population thus allowing more general implications and a broader perspective on microbial interactions in thermophilic dry-fermentation of biowaste.

All sampled biogas reactors treat biowaste in dry fermentation (approximately 30\% dry matter content) and were operated between 54 and $55^{\circ} \mathrm{C}$. More than 550,000 quality trimmed amplicon reads were kept for phylogenetic classification (Additional file 1: Table S3). Archaea usually contributed $1-2 \%$ to total prokaryotic iTags (Fig. $5 \mathrm{a})$, which reflects the importance of low abundant but highly active microorganisms for the functionality of a community. Only in one reactor (PFL6), the archaeal 16S rRNA gene abundance reached 4.9\%, and Archaea were also enriched in the separated liquid fraction (PLF1a) of reactor PFL1. The archaeal fraction of total prokaryotes is probably slightly underestimated as the average 16S rRNA gene copy number per genome for Bacteria $(n=5)$ is higher than those of the dominant methanogens (Methanothermobacter, $n=2$; Methanoculleus, $n=1)$. Methanoculleus, Methanothermobacter, and Methanomassiliicoccus were ubiquitous throughout the sampled biogas reactors with the first two genera predominating the archaeal community. Together, Methanoculleus and Methanothermobacter contributed 83.2-98.9\% to archaeal iTags (Fig. 5a). In nearly half of the systems (4 out of 9), acetoclastic methanogens of the genera Methanosaeta and Methanosarcina were not detected using amplicon sequencing (Fig. 5a). In five reactors, Methanosarcina accounted for $0.1-0.7 \%$ of Archaea, which is equivalent to a maximum of $0.008 \%$ of the total prokaryotic iTags. This very low relative abundance is contradicting to studies that identified Methanosarcinales as abundant core members of the archaeal community in $\mathrm{AD}[4,6,7,44]$. More quantitative methods such as fluorescence in situ hybridization will be necessary to estimate exact Bacteria to Archaea ratios; however, the dominance of strictly hydrogenotrophic over acetoclastic methanogens within the archaeal community points to a favorable opportunity for SAOB in these AD systems.

Like for the Archaea, the bacterial community showed a recurring diversity pattern among the biogas reactors (Fig. 5b). Alpha diversity measures further indicate a low diversity within the digesters (Additional file 1: Table S4). This is in accordance with the findings that thermophilic systems harbor a lower number of species compared to mesophilic reactors $[69,70]$. In contrast, the degradation of complex substrates was previously linked to a high diversity whereas a smaller number of species was identified in reactors that degrade simple substrates 


\begin{tabular}{|c|c|c|c|c|c|c|c|c|c|c|c|c|}
\hline $\begin{array}{l}\text { Archaea } \\
\text { Bacteria }\end{array}$ & & & & & & & & & 1.2 & & $\overbrace{98.7}^{1.3}$ & \\
\hline Percentage of all Archaea & PFL1a & PFL1b & PFL1c & PFL2 & PFL3 & PFL4 & PFL5 & PFL6 & PFL7 & PFL8 & PFL9 & \multirow{9}{*}{ MAG-R14 } \\
\hline Methanobacterium (Euryarchaeota) & 0.1 & 0 & 0 & 0 & 0.6 & 0.6 & 0.4 & 0 & 0.2 & 6.9 & 0.7 & \\
\hline Methanobrevibacter (Euryarchaeota) & 0 & 0 & 0 & 0 & 0 & 0 & 0 & 0 & 0.2 & 0 & 0 & \\
\hline Methanosphaera (Euryarchaeota) & 0 & 0.1 & 0.2 & 0 & 0 & 0 & 0 & 0 & 0 & 0 & 0 & \\
\hline Methanoculleus (Euryarchaeota) & 44.7 & 51.1 & 65.9 & 23.6 & 82.2 & 83 & 59.2 & 34.2 & 50 & 77.5 & 68.7 & \\
\hline Methanos arcina (Euryarchaeota) & 0.1 & 0 & 0 & 0 & 0.3 & 0.2 & 0 & 0.2 & 0.2 & 0.7 & 0 & \\
\hline Methanomassiliicoccus (Euryarchaeota) & 1.1 & 1.3 & 2.1 & 1.1 & 3.3 & 3.2 & 1.7 & 1.2 & 4 & 9.2 & 3.6 & \\
\hline Methanotherm obacter (Euryarchaeota) & 53.9 & 47.6 & 31.8 & 75.3 & 13.5 & 12.9 & 38.7 & 64.5 & 45.4 & 5.7 & 27 & \\
\hline Candidatus Methanomethylophilus (Euryarchaeota) & 0 & 0 & 0 & 0 & 0 & 0.2 & 0 & 0 & 0 & 0 & 0 & \\
\hline b & PFL1a & PFL1b & PFL1c & PFL2 & PFL3 & PFL4 & PFL5 & PFL6 & PFL7 & PFL8 & PFL9 & \multirow{3}{*}{$\begin{array}{l}\text { MAG-R9 } \\
\text { MAG-R10 }\end{array}$} \\
\hline Candidatus Caldatribacterium (Atribacteria) & 0.2 & 0.2 & 0.2 & 0.5 & 0.3 & 0.2 & 0.3 & 0.4 & 0.8 & 0.6 & 2 & \\
\hline Proteiniphilum (Bacteroidetes) & 1.2 & 0.8 & 0.4 & 0.2 & 0.9 & 0.9 & 1.1 & 0.2 & 1.4 & 1.7 & 1.9 & \\
\hline Lentimicrobiaceae (Bacteroidetes) & 4.4 & 3.1 & 5.2 & 4.2 & 16 & 20.2 & 12.4 & 15.5 & 13 & 9.2 & 12.6 & \multirow[t]{2}{*}{ MAG-R11 } \\
\hline Bacillus (Firmicutes) & 1.8 & 1 & 1.3 & 0.1 & 0.1 & 0.1 & 0.1 & 0.1 & 0.2 & 0.2 & 0.1 & \\
\hline Lactobacillus (Firmicutes) & 1.4 & 1.1 & 2.7 & 0.6 & 0.5 & 0.2 & 0.5 & 0.6 & 1.2 & 0.3 & 0.9 & \multirow{3}{*}{ MAG-E1, E2 } \\
\hline Unc. Clostridia (Caldicoprobacter, Firm ic utes) & 2 & 1.9 & 1.7 & 1 & 1.5 & 0.9 & 2 & 1.2 & 2 & 2.2 & 1.7 & \\
\hline Tepidimicrobium (Firmicutes) & 3.5 & 3.2 & 3.8 & 1.1 & 1.5 & 1 & 2.3 & 2.6 & 1.4 & 2 & 0.9 & \\
\hline Rum iniclostridium group 1 (Firmicutes) & 1.9 & 1.9 & 2.1 & 5.5 & 1.6 & 1.3 & 2.1 & 1.9 & 1.9 & 1.7 & 1.4 & \multirow{6}{*}{$\begin{array}{l}\text { MAG-R1 } \\
\text { MAG-R7 }\end{array}$} \\
\hline Ruminiclostridium (Firmicutes) & 0.9 & 0.9 & 1 & 2.1 & 1.6 & 1 & 2.5 & 1.9 & 1.8 & 1.4 & 1.5 & \\
\hline Rum inococcaceae UCG-010 (Firmicutes) & 0.3 & 0.3 & 0.2 & 0.6 & 0.7 & 0.8 & 0.5 & 0.7 & 1 & 1 & 0.5 & \\
\hline Syntrophom onas (Firmicutes) & 1.4 & 1.4 & 1.6 & 0.7 & 1.4 & 2.5 & 1.2 & 2.6 & 1.4 & 2.5 & 2.7 & \\
\hline Uncultured Dethiobacteraceae (Firmicutes) & 1.5 & 1.7 & 1.6 & 0.6 & 1.0 & 1.2 & 2.3 & 1.4 & 2 & 1.3 & 4.8 & \\
\hline Firmicutes D8A-2 (Firmicutes) & 2 & 2.2 & 0.9 & 1.6 & 0.8 & 0.7 & 0.8 & 1.2 & 1 & 0.7 & 0.7 & \\
\hline Firmicutes DTU014 (Firmicutes) & 13.6 & 15 & 10.2 & 12.8 & 11.4 & 13.7 & 9.7 & 11.3 & 11 & 14.1 & 14.5 & \multirow{2}{*}{$\begin{array}{l}\text { MAG-R5, R6 } \\
\text { MAG-R3 }\end{array}$} \\
\hline Limnochordia MBA03 (Firmicutes) & 26.2 & 31.5 & 32 & 26.2 & 17.9 & 14.3 & 23.4 & 22.4 & 24.6 & 20.5 & 20.1 & \\
\hline Limnochordia M55-D21 (Firmicutes) & 1 & 1.1 & 1.3 & 1.4 & 0.9 & 0.8 & 0.8 & 0.6 & 1.2 & 0.9 & 0.8 & \multirow{2}{*}{ MAG-R4 } \\
\hline Unclassified Clostridia (Firmicutes) & 3 & 3.1 & 3.7 & 14.2 & 10.7 & 12.3 & 7.4 & 8.3 & 11.2 & 12 & 6.7 & \\
\hline Tepidanaerobacter (Firmicutes) & 1 & 0.7 & 0.5 & 0.2 & 0.5 & 0.3 & 0.6 & 0.3 & 0.4 & 0.7 & 0.4 & \\
\hline Syntrophaceticus (Firmicutes) & 3.6 & 3.3 & 2.6 & 1 & 1 & 1 & 1.7 & 2.6 & 0.6 & 0.4 & 1.3 & \multirow[t]{2}{*}{ MAG-R2 } \\
\hline Hydrogenispora (Firmicutes) & 1.1 & 1.2 & 0.9 & 1.5 & 1.1 & 0.7 & 0.5 & 1.2 & 1 & 0.9 & 0.8 & \\
\hline Uncultured Limnochordales (Firmicutes) & 1.1 & 1.2 & 1.1 & 1.3 & 0.7 & 0.8 & 0.5 & 0.8 & 1.1 & 0.7 & 0.9 & \multirow{6}{*}{ MAG-R12 } \\
\hline Unclassified Firmicutes (Firmicutes) & 1.1 & 1.1 & 1.2 & 1.4 & 1.5 & 2.2 & 1.2 & 2 & 1.3 & 1.9 & 1.5 & \\
\hline Defluviitalea (Firmicutes) & 0.5 & 0.6 & 0.9 & 0.7 & 0.6 & 0.8 & 2.3 & 0.6 & 0.4 & 0.4 & 0.6 & \\
\hline Acetomicrobium (Synergistetes) & 1.5 & 1.3 & 1.3 & 1.2 & 2.4 & 1.5 & 2.5 & 1.8 & 2 & 2.7 & 3.2 & \\
\hline Haloplasma (Tenericutes) & 0.7 & 0.7 & 1.4 & 1.6 & 0.6 & 0.5 & 0.1 & 0.9 & 0.7 & 0.5 & 0.4 & \\
\hline Izim aplasmatales (Tenericutes) & 1.2 & 0.9 & 1.5 & 2.2 & 1.5 & 2.5 & 1 & 1.6 & 1.2 & 2 & 1.5 & \\
\hline Defluviitoga (Therm otogae) & 8.4 & 7.4 & 6.6 & 8.9 & 12.7 & 10.6 & 13 & 7.4 & 4.7 & 5.2 & 6.4 & \multirow{3}{*}{$\begin{array}{l}\text { MAG-R13 } \\
\text { MAG-R8 }\end{array}$} \\
\hline Halocella (Halanaerobiaeota) & 4.5 & 4.2 & 4.4 & 1.2 & 0.5 & 0.3 & 0.7 & 0.9 & 0.7 & 0.2 & 2 & \\
\hline Other Bacteria & 9.2 & 7.0 & 7.8 & 5.3 & 8.3 & 6.8 & 6.5 & 7.0 & 9.1 & 12 & 7 & \\
\hline $\begin{array}{cc} & 0.05- \\
\text { Bray-Curtisis } & 0.15- \\
\text { dissimilarity } & 0.25\end{array}$ & & & & & & & & & & & & \\
\hline & & & & & & & & & & & & \\
\hline $\begin{array}{l}\text { Fig. } 5 \text { Microbial community composition in nir } \\
\text { relative abundance of archaeal amplicons was } \\
\text { amplicons are only shown for major groups tha } \\
\text { dissimilarity based on OTUs clustered at } 97 \% \text { id }\end{array}$ & $\begin{array}{l}\text { ne full- } \\
\text { reveal } \\
\text { at con } \\
\text { dentity }\end{array}$ & 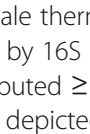 & nophili & . & $16 S$ & $\begin{array}{l}\text { Th } \\
\text { acir } \\
\text { se }\end{array}$ & Pe & $\begin{array}{l}\text { actio } \\
\text { ntage } \\
\text { at lec }\end{array}$ & $\begin{array}{l}\text { tota } \\
\operatorname{tax} \\
\text { he } s\end{array}$ & kar & s an & $\begin{array}{l}\text { he } \\
\text { acterial } \\
\text { tis }\end{array}$ \\
\hline
\end{tabular}

[44]. Overall, the microbial community identified by amplicon sequencing was in good coherence with the outcomes of the metagenomic approach for PFL9 (Figs. $1 \mathrm{a}$ and 5), and the identified MAGs adequately covered the major groups of the microbial community.

Firmicutes, Bacteroidetes, and Thermotogae were consistently identified as the dominant clades on phylum level in accordance with previous findings that reported a high abundance of those three phyla in thermophilic and biowaste-treating digesters [7, 44]. Together, they accounted for $89.6-95.2 \%$ of the bacterial community (Additional file 1: Fig. S6). Among the Firmicutes, a large fraction of reads affiliated with uncultured bacteria of the MBA03 and the DTU014 clade. Together, they contributed $28-46.5 \%$ to all bacterial iTags and make up more than half of the Firmicutes (Fig. 5b). The MBA03 and DTU014 groups cluster sequences of uncultured bacteria at order to family level. However, the MBA03 clade was represented only by one single OTU that accounted for more than $97 \%$ of the reads, and the DTU014 clade comprised two OTUs that contributed 92.3-96.6\% of their iTags revealing very low species diversity within these groups. Despite their abundance and the identification as members of the core microbiome in mesophilic and thermophilic AD, their metabolic potential and physiology is still poorly characterized [6, 71]. Together with the metagenomic analysis, this suggests that few MBA03 and DTU014 species are central to 
carbohydrate fermentation throughout these thermophilic AD reactors. As most of the MAGs from the metagenome did not contain 16S rRNA gene fragments, they could not directly linked to the OTUs or clustered groups. Instead, the phylogenetic position based on concatenated ribosomal proteins, the taxonomic classification of all coding sequences, and coverage information were used for the assignment (Fig. 5).

Unlike the Archaea, potential acetate-consuming bacteria of the genera Syntrophaceticus and Tepidanaerobacter were consistently identified contributing $0.4-3.6 \%$ and $0.2-1 \%$ to the bacterial community, respectively. Syntrophaceticus schinkii was described as a mesophilic species operating at a temperature range from 25 to $40^{\circ} \mathrm{C}$ [29]; however, thermophilic representatives of the Syntrophaceticus were recently identified as drivers of syntrophic acetate oxidation in acetate-fed chemostats [72] suggesting a wide temperature range for acetate degradation within this genus. Uncultured Dethiobacteraceae were consistently identified with similar abundances like the other SPOB but exceptionally high in abundance $(\sim 5 \%)$ in PFL9, the reactor used for our metagenome survey. Moreover, iTags affiliating with Caldicoprobacter always contributed more than $1 \%$ to total bacterial amplicons (Fig. 5b). The OTUs identified in the enrichment cultures were also among the dominant Caldicoprobacter OTUs in the biogas reactors. The OTUs only share approximately $91 \%$ sequence identity to isolated Caldicoprobacter spp. thus indicating a phylogenetic and physiological differentiation between these bacteria. Taken together, uncultured Dethiobacteraceae and unclassified Clostridia distantly related to Caldicoprobacter might harbor novel putatively syntrophic acetate-consuming bacteria that are widespread in thermophilic dry fermentation of biowaste. The reactors harbor a diverse acetate-consuming community impressively dominated by SAOB over acetoclastic methanogens.

\section{Ecological considerations for syntrophic acetate metabolism in thermophilic AD of biowaste}

Despite the fact that hydrogenotrophic and acetoclastic methanogens generally coexist, it has been shown by radioisotope probing combined with metagenomic sequencing that the acetoclastic pathway for methanogenesis can be dominant while hydrogenotrophic methanogens showed higher abundances [73]. However, the absence or clear minority of Methanosarcina and other acetoclastic methanogens but ubiquity of diverse potential SAOBs on the other hand strongly suggests that acetate is primarily oxidized by bacteria in the studied biogas reactors. Digesters that treat manure or protein-rich material such as biowaste can have high levels of total ammonia nitrogen (TAN) above $4 \mathrm{~g} \mathrm{NH}_{4}{ }^{+}$-
$\mathrm{N} / \mathrm{kg}$ (e.g., $[7,45,73])$ and ammonia inhibition is a major issue in $\mathrm{AD}$ (reviewed by [74]). It has been demonstrated that a thermophilic community in $\mathrm{AD}$ of biowaste can tolerate significantly more free ammonia compared to a mesophilic community [15]. This was also shown specifically for the hydrogenotrophic methanogens [26]. The toxic-free ammonia increases with elevating temperature and $\mathrm{pH}$, and its concentration was suggested as major factor that determines the assemblage of the acetateconsuming bacterial and archaeal community [17, 19, $22,24,25,44]$. TAN concentrations in reactor PFL1 and PFL8 have been regularly measured and usually ranged between 1.7 and $3 \mathrm{~g} \mathrm{NH}_{4}{ }^{+}-\mathrm{N} / \mathrm{kg}$ (Additional file 1: Fig. S7) and were in the lower range for $\mathrm{AD}$ of biowaste (e.g., $[7,45])$. The composition of biowaste varies over time thus fluctuations of TAN concentrations are expected. However, the community in reactor PFL1 was very similar when sampled at different time points (PFL1b and PFL1c, Additional file 1: Table S2). Although it requires additional research to unravel the environmental factors that shape this consistent community, it appears that dry matter content, temperature, and the substrate were more important than the TAN level alone. Interestingly, such adapted community towards syntrophic acetate oxidation might be more tolerant to ammonia fluctuations caused by high protein loadings and consequently more stable with respect to process failure due to ammonia inhibition. In AD, a major fraction of the carbon flow to methane occurs via acetate. A better understanding of SPOB will be important and could provide a basis for the management of microbial AD communities.

\section{Conclusions}

By combining metagenomics with $16 \mathrm{~S}$ rRNA gene amplicon sequencing and enrichment cultivation, this study allowed us to link the identified organisms with their potential function in the AD food web. The metabolic reconstruction of metagenome assembled genomes from a full-scale biogas reactor and enrichment cultures identified novel putatively acetate-oxidizing bacteria with high metabolic plasticity. The unique ability to reverse the WL pathway or likely using other pathways for syntrophic acetate oxidation is key for SAOB to compete with the carbohydrate-fermenting majority. Beyond the genomic evidence, syntrophic acetate oxidation was demonstrated by the enrichment of Syntrophaceticus, Tepidanaerobacter, and Clostridia distantly related to Caldicoprobacter. Acetate-dependent catabolic processes in the biogas reactors were largely attributed to bacteria as acetoclastic methanogens were completely outnumbered by the SAOB. Thermophilic dry-fermentation of biowaste possibly provides an exceptional ecosystem to study $\mathrm{SAOB}$ and for the enrichment and isolation of novel SAOB. Assuming that the identified SAOB are 
actually active as acetate-oxidizers, this underpins the importance of these bacteria for process functioning and overall organic carbon mineralization. Further studies applying proteomics or transcriptomics and isotope labeling techniques will be crucial to determine their in situ activity and to quantify syntrophic acetate oxidation versus acetoclastic methanogenesis.

\section{Methods}

\section{Sampling and enrichment of syntrophic acetate-oxidizing} bacteria

Samples were taken from nine thermophilic full-scale biogas plants (Additional file 1: Table S2). All samples for DNA extraction were stored at $-20^{\circ} \mathrm{C}$ immediately after sampling. Subsamples taken from the reactor PFL5 were suspended in mineral medium as described recently [64]. Acetate was repeatedly fed from anoxic sterile stock solutions to a final concentration of $5-10 \mathrm{mM}$. If necessary, the $\mathrm{pH}$ was corrected to approximately 7.5 with $\mathrm{NaOH}$ from an anoxic sterile stock solution (1 M). Enrichments were carried out over a period of 491 days by successive transfers $(n=10)$ of $1-10 \%$ into fresh medium. ENR-ALA was once fed with $10 \mathrm{mM}$ lactic acid, and ENR-AEA was once fed with $10 \mathrm{mM}$ ethanol before the third transfer. Both treatments were further on fed with acetate again. Enrichment ENR-Ac was solely fed with acetate. Acetomicrobium hydrogeniformans DSM22491, A. thermoterrenum DSM13490, A. mobile DSM13181, Methanoculleus thermophilus DSM2373, and Methanothermobacter thermoautotrophicus DSM1053 were purchased from the Leibniz Institute DSMZ-German Collection of Microorganisms and Cell Cultures and cultured according to their recommendations. To determine acetate oxidation, methane and SCFAs were measured with a gas chromatograph as described previously [64].

\section{Metagenome sequencing and analysis}

DNA was extracted using the PowerViral DNA/RNA kit (Quiagen, Hilden, Germany) according to manufacturer's instructions. Libraries were prepared using the Nextera XT kit (Illumina Inc., CA, USA) according to manufacturer's protocol and paired end sequenced $(2 \mathrm{x}$ $300 \mathrm{bp}$ ) on MiSeq platform using V3 chemistry (Illumina Inc., CA, USA). All bioinformatics is described in detail in Additional file 2: Supplementary Methods. In brief, all tools from raw read processing to phylogenetic analysis of final MAGs were embedded and automated in a Snakemake [40] workflow. The parameters and settings of the software applied in this study can be further found in our Snakefile (https://www.knutt.org/Snakefiles). In the first step, quality trimmed reads were used for taxonomic and functional classification followed by assembly and binning based on tetra-nucleotide frequencies and coverage. The annotation was mainly performed with MetaErg [75]; however, further annotation tools and custom databases that we considered as useful were included in the pipeline. Concatenated ribosomal proteins were used to determine the phylogenetic position of the MAGs. The automated metagenome analysis pipeline is available at github.com/KnuttPipeline.

\section{S rRNA gene amplicon sequencing}

The bacterial and archaeal diversity in the biogas reactors was determined by analyzing the $\mathrm{V} 3-\mathrm{V} 4$ region of the 16S rRNA gene using Illumina MiSeq sequencing of barcoded amplicons. Amplicons were prepared using primers Pro341f/Pro805r [76] targeting the domains Bacteria and Archaea. PCR conditions were as described earlier [64]. PCR products were purified using AMPure $\mathrm{XP}$ beads (Beckman Coulter), and libraries were prepared using the Nextera XT kit (Illumina Inc., CA, USA) according to manufacturer's protocol. Libraries were quantified with a Qubit 3.0 fluorimeter (Thermo Fisher Scientific Inc., USA) and paired end sequenced (2x 300 bp) on MiSeq platform using V3 chemistry (Illumina Inc., CA, USA). Remaining Nextera XT adapter as well as primer sequences were removed, and the reads were trimmed at quality score Q20 using cutadapt [77]. The reads were merged with BBMerge [78] and OTUs clustered at $97 \%$ identity were generated with VSEARCH [79]. The OTUs were classified using SINA and the SILVA database SSU Ref NR r132 [80, 81]. Alpha and beta diversity measures were calculated using phyloseq [82] or PAST [83].

\section{Supplementary information}

Supplementary information accompanies this paper at https://doi.org/10. 1186/s40168-020-00862-5.

Additional file 1: Figure S1. Relative abundance of hydrogenase classes identified in the metagenome. Figure S2. Relative abundance of metagenomic 16S rRNA gene fragments from PFL9 affiliating with Bacteria and Archaea as shown in Fig. 1a but the highest classification rank of the major groups is depicted. Figure S3. Relative abundance of bacterial and archaeal groups that contributed $\geq 1 \%$ to total $16 \mathrm{~S}$ rRNA sequences in at least one sample in acetate-fed enrichment cultures. The microbial community was either analyzed by 165 rRNA gene amplicon sequencing (iTags) or metagenome sequencing (Meta). Figure S4. A simplified overview of the metabolic functions reconstructed from Firmicutes MAG-E2. Hyd, [FeFe] hydrogenase group A3; Hdr, heterodisulfide reductase; $\mathrm{Rnf}, \mathrm{Na}^{+} / \mathrm{H}^{+}$translocating ferredoxin: $\mathrm{NAD}^{+}$oxidoreductase; $\mathrm{Q}$, quinone; ETF, electron transfer flavoprotein; ETF-Q OR, electron transfer flavoprotein/quinone oxidoreductase; FDH, formate dehydrogenase; Dsr, dissimilatory sulfite reductase; C, DsrC; Nar, nitrate reductase; Nir, nitrite reductase; Nor, nitric oxide reductase; $\mathrm{SDH}$, succinate dehydrogenase; $\mathrm{GH}$, glycosyl hydrolase; EM, electron mediator; CM, cytoplasmic membrane. Figure S5. Maximum Likelihood (RAxML) tree of dissimilatory sulfite reductase genes (DsrAB) recovered from Firmicutes MAG-E2. Closed circles indicate bootstrap support $\geq 70 \%$. The reference database used for phylogenetic reconstruction contained 340 sequences of DsrAB proteins (Loy et al., 2008; Environ. Microbiol. 11: 289-299). Figure S6. Microbial community composition in nine full-scale thermophilic biowaste digesters 
summarized at phylum level. The relative abundance was revealed by $16 S$ rRNA gene amplicon sequencing. Figure S7. Total ammonia nitrogen $\left(\mathrm{g} \mathrm{NH}_{4}{ }^{+}-\mathrm{N} / \mathrm{kg}\right)$ and $\mathrm{pH}$ in PFL1 and PFL8. Table S1. General statistics about MAGs recovered from the reactor PFL9 and from the enrichment culture. Table S2. Overview of the sampled biogas reactors and performed experiments. Table S3. Number of quality trimmed $16 \mathrm{~S}$ rRNA gene amplicons kept for taxonomic classification. Table S4. Comparison of alpha diversity measures determined for the nine biogas reactors.

Additional file 2. Supplementary Methods.

\section{Acknowledgements}

We greatly acknowledge Alina Peters for excellent technical support. We would also like to thank Torsten Jeske for general support and fruitful scientific discussions.

\section{Authors' contributions}

The study was designed by SD and CG. Lab work and experiments were carried out by SD. $\amalg$ built the metagenome analysis pipeline in a Snakemake workflow with contributions from SD. SD wrote the manuscript and CG edited and approved the manuscript. The author(s) read and approved the final manuscript.

\section{Funding}

This study was funded by the German Research Foundation (Deutsche Forschungsgemeinschaft, grant number DY 132/1-1).

\section{Availability of data and materials}

All nucleotide sequences obtained in this study have been deposited in GenBank. Amplicon sequences from the 16S rRNA gene survey were deposited in NCBI BioProject PRJNA607872 and metagenome reads are available in BioProject PRJNA607871. MAGs are available on https://www. knutt.org/.

\section{Ethics approval and consent to participate}

Not applicable

\section{Consent for publication}

Not applicable

\section{Competing interests}

The authors declare no competing interests.

\section{Received: 28 February 2020 Accepted: 11 May 2020} Published online: 03 July 2020

\section{References}

1. Thauer RK, Jungermann K, Decker K. Energy conservation in chemotrophic anaerobic bacteria. Microbiol Mol Biol Rev. 1977;41:100-80.

2. Mountfort DO. Evidence for ATP synthesis driven by a proton gradient in Methanosarcina barkeri. Biochem Biophys Res Commun. 1978;85:1346-51.

3. Hattori S. Syntrophic acetate-oxidizing microbes in methanogenic environments. Microbes Environ. 2008:23:118-27.

4. Rivière $D$, Desvignes V, Pelletier E, Chaussonnerie S, Guermazi S, Weissenbach J, et al. Towards the definition of a core of microorganisms involved in anaerobic digestion of sludge. ISME J. 2009;3:700-14.

5. Narihiro T, Nobu MK, Kim N-K, Kamagata Y, Liu W-T. The nexus of syntrophyassociated microbiota in anaerobic digestion revealed by long-term enrichment and community survey. Environ Microbiol. 2015:17:1707-20.

6. Kirkegaard RH, Mcllroy SJ, Kristensen JM, Nierychlo M, Karst SM, Dueholm MS, et al. The impact of immigration on microbial community composition in full-scale anaerobic digesters. Sci Rep. 2017;7:1-11.

7. Calusinska M, Goux X, Fossépré M, Muller EEL, Wilmes P, Delfosse P. A year of monitoring 20 mesophilic full-scale bioreactors reveals the existence of stable but different core microbiomes in bio-waste and wastewater anaerobic digestion systems. Biotechnol Biofuels. 2018;11:196.

8. Galagan JE, Nusbaum C, Roy A, Endrizzi MG, Macdonald P, FitzHugh W, et al. The genome of $M$. acetivorans reveals extensive metabolic and physiological diversity. Genome Res. 2002;12:532-42.

9. Dolfing J. Thermodynamic constraints on syntrophic acetate oxidation. Appl Environ Microbiol. 2014;80:1539-41.
10. Petersen SP, Ahring BK. Acetate oxidation in a thermophilic anaerobic sewage-sludge digestor: the importance of non-aceticlastic methanogenesis from acetate. FEMS Microbiol Lett. 1991;86:149-52.

11. Schink B. Energetics of syntrophic cooperation in methanogenic degradation. Microbiol Mol Biol Rev. 1997;61:262-80.

12. Shigematsu $T$, Tang $Y$, Kobayashi $T$, Kawaguchi H, Morimura S, Kida K. Effect of dilution rate on metabolic pathway shift between aceticlastic and nonaceticlastic methanogenesis in chemostat cultivation. Appl Environ Microbiol. 2004:70:4048-52.

13. Hao L-P, Lü F, He P-J, Li L, Shao L-M. Predominant contribution of syntrophic acetate oxidation to thermophilic methane formation at high acetate concentrations. Environ Sci Technol. 2011;45:508-13.

14. Gallert C, Winter J. Mesophilic and thermophilic anaerobic digestion of source-sorted organic wastes: effect of ammonia on glucose degradation and methane production. Appl Microbiol Biotechnol. 1997:48:405-10.

15. Gallert C, Bauer S, Winter J. Effect of ammonia on the anaerobic degradation of protein by a mesophilic and thermophilic biowaste population. Appl Microbiol Biotechnol. 1998;50:495-501.

16. Fotidis IA, Karakashev D, Kotsopoulos TA, Martzopoulos GG, Angelidaki I. Effect of ammonium and acetate on methanogenic pathway and methanogenic community composition. FEMS Microbiol Ecol. 2013;83:3848.

17. Fotidis IA, Karakashev D, Angelidaki I. The dominant acetate degradation pathway/methanogenic composition in full-scale anaerobic digesters operating under different ammonia levels. Int J Environ Sci Technol. 2014; 11:2087-94

18. Chen JL, Ortiz R, Steele TWJ, Stuckey DC. Toxicants inhibiting anaerobic digestion: a review. Biotechnol Adv. 2014;32:1523-34.

19. Sprott GD, Patel GB. Ammonia toxicity in pure cultures of methanogenic bacteria. Syst Appl Microbiol. 1986;7:358-63.

20. Rajagopal R, Massé DI, Singh G. A critical review on inhibition of anaerobic digestion process by excess ammonia. Bioresour Technol. 2013;143:632-41.

21. Angelidaki I, Ahring BK. Thermophilic anaerobic digestion of livestock waste: the effect of ammonia. Appl Microbiol Biotechnol. 1993;38:560-4

22. Sun L, Müller B, Westerholm M, Schnürer A. Syntrophic acetate oxidation in industrial CSTR biogas digesters. J Biotechnol. 2014:171:39-44.

23. Werner JJ, Garcia ML, Perkins SD, Yarasheski KE, Smith SR, Muegge BD, et al. Microbial community dynamics and stability during an ammonia-induced shift to syntrophic acetate oxidation. Appl Environ Microbiol. 2014;80:3375-83.

24. Westerholm M, Levén L, Schnürer A. Bioaugmentation of syntrophic acetate-oxidizing culture in biogas reactors exposed to increasing levels of ammonia. Appl Environ Microbiol. 2012;78:7619-25.

25. Schnürer A, Nordberg $\AA$. Ammonia, a selective agent for methane production by syntrophic acetate oxidation at mesophilic temperature. Water Sci Technol. 2008:57:735-40.

26. Wang $\mathrm{H}$, Fotidis IA, Angelidaki I. Ammonia effect on hydrogenotrophic methanogens and syntrophic acetate-oxidizing bacteria. FEMS Microbio Ecol. 2015;91.

27. Müller B, Sun L, Westerholm M, Schnürer A. Bacterial community composition and fhs profiles of low- and high-ammonia biogas digesters reveal novel syntrophic acetate-oxidising bacteria. Biotechnol Biofuels. 2016;9:48.

28. Schnürer A, Schink B, Svensson BH. Clostridium ultunense sp. nov., a mesophilic bacterium oxidizing acetate in syntrophic association with a hydrogenotrophic methanogenic bacterium. Int J Syst Evol Microbiol. 1996;46:1145-52.

29. Westerholm M, Roos S, Schnürer A. Syntrophaceticus schinkii gen. nov., sp. nov., an anaerobic, syntrophic acetate-oxidizing bacterium isolated from a mesophilic anaerobic filter. FEMS Microbiol Lett. 2010;309:100-4.

30. Timmers PHA, Vavourakis CD, Kleerebezem R, Damsté JSS, Muyzer G, Stams AJM, et al. Metabolism and occurrence of methanogenic and sulfatereducing syntrophic acetate oxidizing communities in haloalkaline environments. Front Microbiol. 2018:9.

31. Westerholm M, Roos S, Schnürer A. Tepidanaerobacter acetatoxydans sp. nov., an anaerobic, syntrophic acetate-oxidizing bacterium isolated from two ammonium-enriched mesophilic methanogenic processes. Syst Appl Microbiol. 2011;34:260-6

32. Balk M, Weijma J, Stams AJM. Thermotoga lettingae sp. nov., a nove thermophilic, methanol-degrading bacterium isolated from a thermophilic anaerobic reactor. Int J Syst Evol Microbiol. 2002:52:1361-8.

33. Hattori S, Kamagata Y, Hanada S, Shoun H. Thermacetogenium phaeum gen. nov., sp. nov., a strictly anaerobic, thermophilic, syntrophic acetate-oxidizing bacterium. Int J Syst Evol Microbiol. 2000;50:1601-9. 
34. Nüsslein B, Chin K-J, Eckert W, Conrad R. Evidence for anaerobic syntrophic acetate oxidation during methane production in the profundal sediment of subtropical Lake Kinneret (Israel). Environ Microbiol. 2001;3:460-70.

35. Vavilin V, Rytov S, Conrad R. Modelling methane formation in sediments of tropical lakes focusing on syntrophic acetate oxidation: Dynamic and static carbon isotope equations. Ecol Model. 2017;363:81-95.

36. Rotaru A-E, Calabrese F, Stryhanyuk H, Musat F, Shrestha PM, Weber HS, et al. Conductive particles enable syntrophic acetate oxidation between Geobacter and Methanosarcina from coastal sediments. mBio. 2018;9: e00226-18.

37. Mayumi D, Mochimaru H, Yoshioka H, Sakata S, Maeda H, Miyagawa Y, et al. Evidence for syntrophic acetate oxidation coupled to hydrogenotrophic methanogenesis in the high-temperature petroleum reservoir of Yabase oil field (Japan). Environ Microbiol. 2011;13:1995-2006.

38. Rui J, Qiu Q, Lu Y. Syntrophic acetate oxidation under thermophilic methanogenic condition in Chinese paddy field soil. FEMS Microbiol Ecol. 2011:77:264-73

39. Conrad R, Klose M. Stable carbon isotope discrimination in rice field soil during acetate turnover by syntrophic acetate oxidation or acetoclastic methanogenesis. Geochim Cosmochim Acta. 2011;75:1531-9.

40. Köster J, Rahmann S. Snakemake - a scalable bioinformatics workflow engine. Bioinformatics. 2012;28:2520-2.

41. Greening C, Biswas A, Carere CR, Jackson CJ, Taylor MC, Stott MB, et al. Genomic and metagenomic surveys of hydrogenase distribution indicate $\mathrm{H}_{2}$ is a widely utilised energy source for microbial growth and survival. ISME J. 2016;10:761-77.

42. Ben Hania W, Godbane R, Postec A, Hamdi M, Ollivier B, Fardeau M-L. Defluviitoga tunisiensis gen. nov., sp. nov., a thermophilic bacterium isolated from a mesothermic and anaerobic whey digester. Int J Syst Evol Microbiol. 2012;62:1377-82

43. Maus I, Cibis KG, Bremges A, Stolze Y, Wibberg D, Tomazetto G, et al. Genomic characterization of Defluviitoga tunisiensis L3, a key hydrolytic bacterium in a thermophilic biogas plant and its abundance as determined by metagenome fragment recruitment. J Biotechnol. 2016;232:50-60.

44. Campanaro S, Treu L, Rodriguez-R LM, Kovalovszki A, Ziels RM, Maus I, et al. New insights from the biogas microbiome by comprehensive genomeresolved metagenomics of nearly 1600 species originating from multiple anaerobic digesters. Biotechnol Biofuels. 2020;13:25.

45. Vanwonterghem I, Jensen PD, Ho DP, Batstone DJ, Tyson GW. Linking microbial community structure, interactions and function in anaerobic digesters using new molecular techniques. Curr Opin Biotechnol. 2014;27: 55-64.

46. Vanwonterghem I, Jensen PD, Rabaey K, Tyson GW. Genome-centric resolution of microbial diversity, metabolism and interactions in anaerobic digestion. Environ Microbiol. 2016;18:3144-58

47. Simankova MV, Chernych NA, Osipov GA, Zavarzin GA. Halocella cellulolytica gen. nov., sp. nov., a new obligately anaerobic, halophilic, cellulolytic bacterium. Syst Appl Microbiol. 1993;16:385-9.

48. Cayol J-L, Ollivier B, Patel BKC, Prensier G, Guezennec J, Garcia J-L. Isolation and characterization of Halothermothrix orenii gen. nov., sp. nov., a halophilic, thermophilic, fermentative, strictly anaerobic bacterium. Int J Syst Evol Microbiol. 1994;44:534-40.

49. Schnürer A, Svensson BH, Schink B. Enzyme activities in and energetics of acetate metabolism by the mesophilic syntrophically acetate-oxidizing anaerobe Clostridium ultunense. FEMS Microbiol Lett. 1997:154:331-6.

50. Hattori S, Galushko AS, Kamagata Y, Schink B. Operation of the CO dehydrogenase/acetyl coenzyme A pathway in both acetate oxidation and acetate formation by the syntrophically acetate-oxidizing bacterium Thermacetogenium phaeum. J Bacteriol. 2005;187:3471-6.

51. Manzoor S, Bongcam-Rudloff E, Schnürer A, Müller B. Genome-guided analysis and whole transcriptome profiling of the mesophilic syntrophic acetate oxidising bacterium Syntrophaceticus schinkii. PLoS ONE. 2016;11: e0166520.

52. Müller B, Sun L, Schnürer A. First insights into the syntrophic acetateoxidizing bacteria - a genetic study. MicrobiologyOpen. 2013;2:35-53.

53. Schuchmann K, Müller V. Energetics and application of heterotrophy in acetogenic bacteria. Appl Environ Microbiol. 2016;82:4056-69.

54. Manzoor S, Schnürer A, Bongcam-Rudloff E, Müller B. Genome-guided analysis of Clostridium ultunense and comparative genomics reveal different strategies for acetate oxidation and energy conservation in syntrophic acetate-oxidising bacteria. Genes. 2018;9:225.
55. Keller A, Schink B, Müller N. Energy-conserving enzyme systems active during syntrophic acetate oxidation in the thermophilic bacterium Thermacetogenium phaeum. Front Microbiol. 2019;10.

56. Keller A, Schink B, Müller N. Alternative pathways of acetogenic ethanol and methanol degradation in the thermophilic anaerobe Thermacetogenium phaeum. Front Microbiol. 2019;10.

57. Sorokin DY, Abbas B, Geleijnse M, Kolganova TV, Kleerebezem R, van Loosdrecht MCM. Syntrophic associations from hypersaline soda lakes converting organic acids and alcohols to methane at extremely haloalkaline conditions. Environ Microbiol. 2016;18:3189-202.

58. Zhilina TN, Zavarzina DG, Kolganova TV, Tourova TP, Zavarzin GA. "Candidatus Contubernalis alkalaceticum," an obligately syntrophic alkaliphilic bacterium capable of anaerobic acetate oxidation in a coculture with Desulfonatronum cooperativum. Microbiology. 2005;74:695-703.

59. Mosbæk F, Kjeldal H, Mulat DG, Albertsen M, Ward AJ, Feilberg A, et al. Identification of syntrophic acetate-oxidizing bacteria in anaerobic digesters by combined protein-based stable isotope probing and metagenomics. ISME J. 2016;10:2405-18.

60. Nobu MK, Dodsworth JA, Murugapiran SK, Rinke C, Gies EA, Webster G, et al. Phylogeny and physiology of candidate phylum 'Atribacteria' (OP9/ JS1) inferred from cultivation-independent genomics. ISME J. 2016;10:27386.

61. Lee YM, Hwang K, Lee Jl, Kim M, Hwang CY, Noh H-J, et al. Genomic insight into the predominance of candidate phylum Atribacteria JS1 lineage in marine sediments. Front Microbiol. 2018;9.

62. Maune MW, Tanner RS. Description of Anaerobaculum hydrogeniformans sp. nov., an anaerobe that produces hydrogen from glucose, and emended description of the genus Anaerobaculum. Int J Syst Evol Microbiol. 2012;62: 832-8.

63. Nobu MK, Narihiro T, Rinke C, Kamagata Y, Tringe SG, Woyke T, et al. Microbial dark matter ecogenomics reveals complex synergistic networks in a methanogenic bioreactor. ISME J. 2015:9:1710-22.

64. Dyksma S, Gallert C. Candidatus Syntrophosphaera thermopropionivorans: a novel player in syntrophic propionate oxidation during anaerobic digestion. Environ Microbiol Rep. 2019;11:558-70.

65. Worm P, Koehorst JJ, Visser M, Sedano-Núñez VT, Schaap PJ, Plugge CM, et al. A genomic view on syntrophic versus non-syntrophic lifestyle in anaerobic fatty acid degrading communities. Biochim Biophys Acta BBA Bioenerg. 1837;2014:2004-16.

66. Sieber JR, Crable BR, Sheik CS, Hurst GB, Rohlin L, Gunsalus RP, et al. Proteomic analysis reveals metabolic and regulatory systems involved in the syntrophic and axenic lifestyle of Syntrophomonas wolfei. Front Microbiol. 2015;6.

67. Crable BR, Sieber JR, Mao X, Alvarez-Cohen L, Gunsalus R, Ogorzalek Loo RR, et al. Membrane complexes of Syntrophomonas wolfei involved in syntrophic butyrate degradation and hydrogen formation. Front Microbiol. 2016;7.

68. Zheng D, Wang H-Z, Gou M, Nobu MK, Narihiro T, Hu B, et al. Identification of novel potential acetate-oxidizing bacteria in thermophilic methanogenic chemostats by DNA stable isotope probing. Appl Microbiol Biotechnol. 2019:103:8631-45.

69. Treu L, Campanaro S, Kougias PG, Sartori C, Bassani I, Angelidaki I. Hydrogen-fueled microbial pathways in biogas upgrading systems revealed by genome-centric metagenomics. Front Microbiol. 2018;9.

70. Ziels RM, Svensson BH, Sundberg C, Larsson M, Karlsson A, Yekta SS. Microbial rRNA gene expression and co-occurrence profiles associate with biokinetics and elemental composition in full-scale anaerobic digesters. Microb Biotechnol. 2018;11:694-709.

71. Campanaro S, Treu L, Kougias PG, De Francisci D, Valle G, Angelidaki I. Metagenomic analysis and functional characterization of the biogas microbiome using high throughput shotgun sequencing and a novel binning strategy. Biotechnol Biofuels. 2016;9:26.

72. Westerholm M, Müller B, Singh A, Lindsjö OK, Schnürer A. Detection of novel syntrophic acetate-oxidizing bacteria from biogas processes by continuous acetate enrichment approaches. Microb Biotechnol. 2018;11:680-93.

73. Luo G, Fotidis IA, Angelidaki I. Comparative analysis of taxonomic functional, and metabolic patterns of microbiomes from 14 full-scale biogas reactors by metagenomic sequencing and radioisotopic analysis. Biotechnol Biofuels. 2016:9:51

74. Yenigün $\mathrm{O}$, Demirel B. Ammonia inhibition in anaerobic digestion: a review. Process Biochem. 2013:48:901-11.

75. Dong $X$, Strous M. An integrated pipeline for annotation and visualization of metagenomic contigs. Front Genet. 2019;10. 
76. Takahashi S, Tomita J, Nishioka K, Hisada T, Nishijima M. Development of a prokaryotic universal primer for simultaneous analysis of Bacteria and Archaea using next-generation sequencing. PLoS ONE. 2014;9:e105592.

77. Martin M. Cutadapt removes adapter sequences from high-throughput sequencing reads. EMBnet.journal. 2011;17:10-2.

78. Bushnell B, Rood J, Singer E. BBMerge - accurate paired shotgun read merging via overlap. PLoS ONE. 2017;12:e0185056.

79. Rognes T, Flouri T, Nichols B, Quince C, Mahé F. VSEARCH: a versatile open source tool for metagenomics. Peer J. 2016;4:e2584.

80. Pruesse E, Peplies J, Glöckner FO. SINA: accurate high-throughput multiple sequence alignment of ribosomal RNA genes. Bioinformatics. 2012;28:18239.

81. Quast C, Pruesse E, Yilmaz P, Gerken J, Schweer T, Yarza P, et al. The SILVA ribosomal RNA gene database project: improved data processing and webbased tools. Nucleic Acids Res. 2013:41:D590-6.

82. McMurdie PJ, Holmes S. phyloseq: an R package for reproducible interactive analysis and graphics of microbiome census data. PLOS ONE. 2013;8:e61217.

83. Hammer $\varnothing$, Harper DAT, Ryan PD. PAST: Paleontological statistics software package for education and data analysis. Palaeontol Electron. 4:9.

\section{Publisher's Note}

Springer Nature remains neutral with regard to jurisdictional claims in published maps and institutional affiliations.

Ready to submit your research? Choose BMC and benefit from:

- fast, convenient online submission

- thorough peer review by experienced researchers in your field

- rapid publication on acceptance

- support for research data, including large and complex data types

- gold Open Access which fosters wider collaboration and increased citations

- maximum visibility for your research: over $100 \mathrm{M}$ website views per year

At $\mathrm{BMC}$, research is always in progress.

Learn more biomedcentral.com/submissions 